\section{Sex role identification and behavior in a reiterated prisoner's dilemma game}

\author{
DAVID MACK, PAULA N. AUBURN*, and GEORGE P. KNIGHT \\ Macalester College, St. Paul, Minn. 55101
}

Twenty-four male and 24 female Ss played 100 trials of a typical prisoner's dilemma game (PDG) with a simulated partner. Half the Ss were told that the other player was of the same sex as themselves (Treatment 1 ), and the remainder were told that the other player was of the opposite sex (Treatment 2). Ss under Treatment 1 were more competitive than Ss under Treatment 2 for each sex, and, overall, males were more cooperative than females. It is suggested that the results may be interpreted in terms of achievement motivation and its relation to sex-role identification.

In the past, society has dictated differential role behaviors for males and females, and these roles have in turn heavily influenced the nature of interactions between the sexes. Recently, some segments of society have begun to question the validity of differential role behaviors based on sex alone, and a primary target has been the economic discrimination which has denied females the competition available to males. Changes are taking place-business, professional, and academic institutions are being forced to drop sex discrimination practices, and more and more opportunities for women have become available. Yet there has been no great deluge of women into these spheres. The acceptance of women has increased only in the lower strata occupations, while there has been a decrease in the percentage of women employed in professional and technical categories over the past two decades (Kaley, 1971). What motivates modern woman to follow tradition and dismiss competitive opportunities remains vague. One aspect of society's dictated role differentiation implies that women will not and cannot adequately compete with men in a professional environment, and perhaps this ability or inability to compete is the most important factor in determining woman's future role in society. Competition is the dominating spirit of the business and professional world, and to succeed in it, women must be able to compete-not only with one another, but especially with their male counterparts.

Experimental games have long provided an experimental setting for the study of cooperation and competition, but previous research has not provided any clear evidence on the role of sex in game-playing behavior. At best, the results are contradictory and inconclusive.

* Now at the University of Minnesota Graduate School.
Some studies have failed to find any relationship between the sex of the players and their choices (Lutzker, 1961; Minas et al, 1960), while others have found sex differences; namely, that in single-sexed dyads, women tend to respond less cooperatively than men (Bixenstine \& Wilson, 1963; Bixenstine et al, 1964). These latter authors have suggested that the expression of sex differences has been hindered by the restricted choices and equal status relationship of the two players in the prisoner's dilemma game.

The PDG, construed to offer a "competitive achievement situation," is used in the present study to view the behavior of Ss who have been "psychologically prepared" to play with members of the same or opposite sex.

\section{METHOD}

Two treatment conditions (TCs) were used: (1) where Ss were told that the other player was of the same sex as themselves, and (2) where Ss were told that the other player was of the opposite sex. Within each TC, Ss were segregated by sex. Thus, four experimental groups ( $N=12$ in each) were employed: M1 (male vs "male"); M2 (male vs "female"); F1 (female vs "female"); and F2 (female vs "male"). In actual fact, under both TCs the "other player" was simulated by a probability randomizer which followed an $80 \% \mathrm{C}$ strategy, ${ }^{1}$ thus ensuring that the game situation was held constant for all Ss.

The payoff matrix used for the PDG can be specified by the following parameters (using the convention established by Pilisuk \& Rapoport, 1964): $\quad R=3, \quad S=0, \quad T=5, \quad$ and $P=-1$. The experimental setup was that typically employed with a simulated other, care being taken to establish and maintain the illusion of a second real player for each $S$. Instructions were tape-recorded to prevent $E$ bias effects and for uniformity of presentation. They were similar to the standard instructions used in previous studies but were modified to include several references to sex of the other player. After the instructions had been given, E ensured that the real player understood the nature of the game and the payoff matrix-after which, Ss played 100 trials of the PDG. The automated equipment provided for recording of the choices of both "players" on each trial, and Ss received feedback on the outcome of each trial by means of a score counter which recorded gains and losses as the game progressed.

In accord with earlier findings, the following hypotheses were established: (1) On the basis of previous evidence, it is hypothesized that females "playing" with female others will choose more competitively than will males "playing" with male others (competitively, F1 > M1). (2) Because of sex-role identification, it is hypothesized that players in "mixed-sexed" dyads will behave differently from those in "single-sexed" dyads (competitively, M1 $\neq$ M2, F1 $\neq$ F2). (3) Because of sex-role identification, it is hypothesized that male players in TC2 will behave differently from female players in TC2 (competitively, M2 $\neq$ F2). Since the study was largely exploratory in nature, no direction was predicted for Hypotheses 2 and 3.

\section{RESULTS}

The primary measure employed was the percentage of $\mathrm{C}$ responses made by real players in the game situation. The findings are summarized in Fig. 1, which shows the mean levels of cooperation for the four experimental groups over trial blocks.

Perhaps the most remarkable outcome was the overall low level of cooperation manifested by $S$ in all experimental groups-a finding at odds with the earlier work of Oskamp \& Perlman (1965). (This overall low level of cooperation may explain why the level of cooperative responding remains relatively constant over time when it is typically reported in the literature as decreasing over a series of trials.) As can be seen from observation of the graph, there were marked differences between groups, with regard to both sex and treatment condition.

In summary, $\mathrm{F} 1>\mathrm{F} 2, \mathrm{~F} 1>\mathrm{M} 1$, and $\mathrm{M} 1>\mathrm{M} 2$ in terms of competitive choices. The Mann-Whitney U test (one-tailed) indicates each of the above differences to be significant at $\alpha=0.001$. The small variances between $M 1$ and $F 2$ are not statistically significant ( $U=47.5$ ).

In order to provide a more refined inde $x$ of behavior, the state-conditioned propensities (SCP) as 


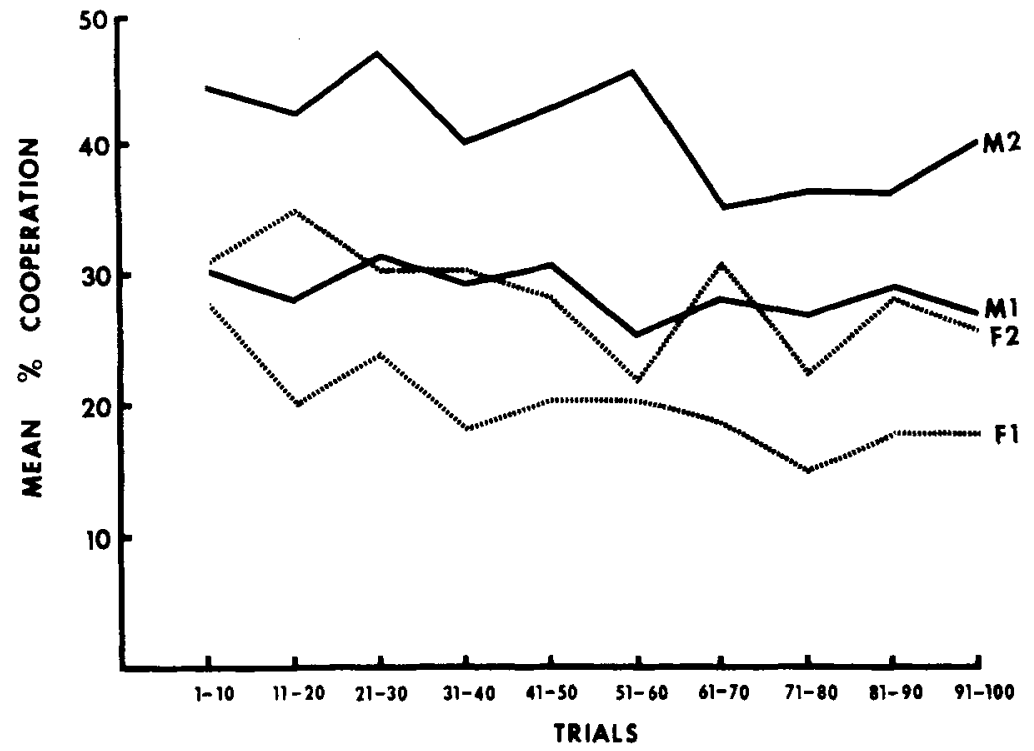

Fig. 1. Mean level of cooperative responses for four experimental groups over 10 blocks of 10 trials.

defined by Rapoport \& Chammah (1965, p. 71-72) were calculated for all Ss. Examination of these confirm earlier research findings and provide further support for our hypotheses. For single-sexed dyads, males were more responsive to cooperative overtures of the other than were females (SCP " $z$ "), were more liable to forgive defections from the joint cooperative play (SCP " $y$ "), and showed a greater willingness to break out of the D,D "trap" (SCP "w") where it existed. Again employing the Mann-Whitney U test, these differences were found to be statistically significant at $\alpha=0.01$.

Further analysis of the SCPs indicated differences in behavior under the two TCs. Examination of SCP " $x$ " showed that Ss in TC2 demonstrated a significantly greater (at $\alpha=0.05$ ) willingness to continue cooperative responding than did $\mathrm{Ss}$ in TC1 (M2 $>$ M1, F2 $>$ F1). They also were significantly more responsive $(\alpha=0.05)$ to cooperative overtures of the other player (SCP " $z$ ").

$$
\text { DISCUSSION }
$$

The study showed two major findings: (1) In single-sexed dyads females were more competitive than males, and (2) both male and female Ss, when playing in single-sexed pairs, were more competitive than when psychologically prepared for and playing with others of the opposite sex.

The data presented allow for various possible interpretations. For example, the data may be explained in accord with the work of Uesugi \& Vinacke (1963) who found differences in the style of play characterizing the two sexes, using mixed-sex and same-sex bargaining was allowed. Styles of play were sex-linked. The typical masculine style was termed exploitative. It consisted of competitive bargaining, making "deals," and striving to win. The typical feminine strategy was described as "accommodative." Females appeared more interested in the social interaction and discussion aspects than in bargaining. To them, the objective appeared to be not a matter of winning, but the problem of arranging a "fair" and satisfying outcome for all players. The women, in fact, manufactured their own rules which made pure bargaining unnecessary. They defined the problem differently and, therefore, attacked it differently. It may indeed be the case that the PDG presented was viewed differently by the players involved, depending on their sex.

An alternative and equally plausible interpretation of the present findings is suggested by the work of Matina Horner. Horner (1969) has suggested that, in an achievement-oriented situation, the achievement motive in females is often contaminated by what she calls "the motive to avoid success"-the rationale being that the female has a fear that success in competitive achievement situations that are open to both sexes will lead to negative consequences, such as unpopularity and loss of femininity.

Women given achievement tests (verbal and arithmetic) in a large coeducational group scored lower than those tested individually or in a same-sex group. Men, however, did much better when tested in the triads in gaming situations in which competitive situation than when tested alone. "These findings suggest that most women will fully explore their intellectual potential only when they do not need to compete-and least of all when they are competing with men."

In the present study the primary measure of behavior (percentage of $\mathrm{C}$ responses) does indeed indicate that in the PDG situation women do not compete against men to the same degree that they do with each other and that men are more competitive with other men than with women. A detailed examination of the SCPs supports this initial finding, indicating that (1) males in the opposite-sex condition are more willing to maintain cooperation and are more responsive to cooperative overtures of the other than are males in the same-sex condition, while (2) females in the opposite-sex condition are less competitive than those in the same-sex condition. To interpret these findings in terms of "woman's motive to avoid success" or "will to fail" and in terms of males" "deference" to females is to read more into the results than the data legitimately warrants. (Precisely the opposite arguments and interpretations-that women defer to men and that males have a "will to fail"-can be made with equal justification.)

As already stated, several plausible interpretations of the presently reported data are possible, including those outlined above (which, incidentally, are not necessarily in conflict with each other), and the question as to why such sex role behaviors are found remains. Further experimentation is indeed required before a clear answer to this question can emerge.

\section{REFERENCES}

BIXENSTINE, V. E., \& WILSON, $K$. V . Effects of level of cooperative choice by other player on choices in a prisoner's dilemma game: Part II. Journal of Abnormal \& Social Psychology, 1963, 67. 139-147.

BIXENSTINE, V. E., CHAMBERS, N., \& WILSON, $K$. $V$. Effect of asymmetry in payoff on behavior in a two-person, non-zero-sum game. Joumal of Conflict Resolution. June 1964, 8, 151-159.

HORNER, M. Fail: Bright women. Psychology Today, 1969, 3, 36-38, 62 .

KALEY, M. M. Attitudes toward the dual role of the married professional woman. American Psychologist. 1971, 26, 301-305.

LUTZKER, D. Sex role, cooperation, and competition in a two-person, non-zero-sum game. Journal of Conflict Resolution, 1961,5, 366-368.

MINAS, J. S., SCODEL, A., MARLOW, D., \& RAWSON, H. Some descriptive aspects of two-person, non-zero-sum games, Part II. Joumal of Conflict Resolution, June 1960. 4. 193-197.

OSKAMP, S., \& PERLMAN, D. Factors affecting cooperation in a prisoner's 
dilemma game. Journal of Conflict Resolution, 1965, 9, 359-374.

PILISUK, M., \& RAPOPORT, A. A non-zero-sum game model of some disarmament problems. Peace Research Society Papers, 1964, 1, 57-78.
RAPOPORT, A., \& CHAMIAH, A. M. Prisoner's dilemma: A study in conflict and cooperation, Ann Arbor: University of Michigan Press, 1965.

UESUGI, T. K., \& VINACKE, W. E. Strategy in a feminine game. Sociometry,
$1963,26,75-88$

NOTE

1. The following symbols are used throughout the paper: $C$ for cooperative and $D$ for defecting (competitive) responses.

\section{CURRENT LITERATURE ON COMPUTERS}

AINSWORTH, W. A. (Department of Communication, University of Keele, Staffordshire, England), \& M IL LAR, J. B. A simple time-sharing system for speech perception experiments. Behavior R e search $M$ e thods \& Instrumentation, $1971,3,21 \cdot 24$.

ALEAMONI, L. M. (University of Illinois, Champaign, IIl. 61820). MERMAC: A model and system for instructional test and questionnaire analysis. Behavior Research Methods \& Instrumentation, 1971, 3, 213-216.

BLISELIUS, P. A. (AB ASEA-ATOM, Box 53, 72183 Västerås, Sweden). A PDP.9 computer program for on-line calculation of mean values, variances, and amplitude distribution. Behavior Research Methods \& Instrumentation, 1971, $3,37-43$.

CAVONIUS, C. R., \& RUBACKY, E. P. A semiautomatic system for preparing computer data cards. Behavior Research Methods \& Instrumentation, 1971, 3, 46-47.

CUMMING, G. (Institute of Experimental Psychology, Oxford, England). LINC-8 presents and controls visual experiments. Behavior Research Methods \&
Instrumentation, 1971, 3, 24-29.

GALOSY, R. A. (Department of Psychology: Developmental, University of North Carolina, Chapel Hill, N.C. 27514), \& ADAMS, W. A. A multipurpose four-dimensional analysis of variance program. Behavior $\mathrm{R}$ esearch $\mathrm{Methods} \&$ Instrumentation, $1971,3,205-210$. GIPS, J. (Unit on Psychophysiology, Laboratory of Psychology, National Institute of Mental Health, Public Health Service, U.S. Department of Health, Education and Welfare, Bethesda, M d, 20014 ), PFEF ER B A U , A., \& BUCHSBAUM, M. Behavior Research Methods \& Instrumentation, 1971, 3, 199-201. MICHAUX, J. (Electronics Research Laboratory and Department of Neurology, University of Louvain, Belgium), \& BERGMANS, J. A program for simultaneous stimulation and data handling in neurophysiological research. Behavior Research Methods \& Instrumentation, 1971, 3, 33-36.

SEKULER, R. (Northwestern University, Evanston, ПIl. 60201), \& ARMSTRONG, R. Luminance control of a small computer CRT display: A very cheap technique. Behavior Research Methods \& Instrumentation, 1971, 3, 48-49.

WALSH, J. F. (Fordham University, Bronx, N.Y. 10458). An efficient procedure for selecting equal probability samples. Behavior R e s a r c h $M$ e thods \& Instrumentation, 1971, 3, 212.

WALSH, J. F. (Fordham University, Bronx, N.Y. 10458). Use of a general analysis of variance program in missing data situations. Behavior Research Methods \& Instrumentation, 1971, 3, 202-203.

WALSH, J. F. (Fordham University, Bronx, N.Y. 10458). Using a general analysis of variance algorithm for covariance designs. Behavior Research Methods \& Instrumentation, 1971 , 3, 203-204.

WOJNAROWSKI, L. (University of Michigan, Ann Arbor, Mich. 41804 ), BACHMAN, K., \& POLLACK, I. High-speed point plotting with computer-controlled displays. Behavior Research Methods \& Instrumentation, 3, 210-211. 